\title{
Evaluation of multi-exponential curve fitting analysis of oxygen- quenched phosphorescence decay traces for recovering microvascular oxygen tension histograms
}

\author{
Rick Bezemer • Dirk J. Faber • Emre Almac • \\ Jeroen Kalkman • Matthieu Legrand • \\ Michal Heger • Can Ince
}

Received: 30 July 2010/Accepted: 8 October 2010/Published online: 3 November 2010

(C) The Author(s) 2010. This article is published with open access at Springerlink.com

\begin{abstract}
Although it is generally accepted that oxygenquenched phosphorescence decay traces can be analyzed using the exponential series method (ESM), its application until now has been limited to a few (patho)physiological studies, probably because the reliability of the recovered oxygen tension $\left(\mathrm{pO}_{2}\right)$ histograms has never been extensively evaluated and lacks documentation. The aim of this study was, therefore, to evaluate the use of the ESM to adequately determine $\mathrm{pO}_{2}$ histograms from phosphorescence decay traces. For this purpose we simulated decay
\end{abstract}

R. Bezemer $(\bowtie) \cdot$ E. Almac · M. Legrand · C. Ince Department of Translational Physiology, Academic Medical Center, University of Amsterdam, Meibergdreef 9, $1105 \mathrm{AZ}$ Amsterdam, The Netherlands

e-mail: r.bezemer@amc.uva.nl

\section{J. Faber · J. Kalkman}

Department of Biomedical Engineering \& Physics, Academic Medical Center, University of Amsterdam, Amsterdam, The Netherlands

\section{J. Faber}

Department of Ophthalmology, Academic Medical Center, University of Amsterdam, Amsterdam, The Netherlands

\section{Heger}

Department of Experimental Surgery, Academic Medical Center, University of Amsterdam, Amsterdam, The Netherlands

\section{Heger}

Biochemistry of Membranes, Institute of Biomembranes, University of Utrecht, Utrecht, The Netherlands

\section{Legrand}

Department of Anesthesiology and Critical Care, Lariboisière Hospital, Assistance Publique-Hopitaux de Paris, Paris, France traces corresponding to uni- and bimodal $\mathrm{pO}_{2}$ distributions and recovered the $\mathrm{pO}_{2}$ histograms at different signal-tonoise ratios (SNRs). Ultimately, we recovered microvascular $\mathrm{pO}_{2}$ histograms measured in the rat kidney in a model of endotoxemic shock and fluid resuscitation and showed that the mean microvascular oxygen tension, $\left\langle\mathrm{pO}_{2}\right\rangle$, decreased after induction of endotoxemia and that after $2 \mathrm{~h}$ of fluid resuscitation, $\left\langle\mathrm{pO}_{2}\right\rangle$ remained low, but the hypoxic peak that had arisen during endotoxemia was reduced. This finding illustrates the importance of recovering $\mathrm{pO}_{2}$ histograms under (patho)physiological conditions. In conclusion, this study has characterized how noise affects the recovery of $\mathrm{pO}_{2}$ histograms using the ESM and documented the reliability of the ESM for recovering both lowand high- $\mathrm{pO}_{2}$ distributions for SNRs typically found in experiments. This study might therefore serve as a frame of reference for investigations focused on oxygen (re)distribution during health and disease and encourage researchers to (re-)analyze data obtained in (earlier) studies possibly revealing new insights into complex disease states and treatment strategies.

Keywords Phosphorimetry - Exponential series method · Heterogeneity - Distribution · Hypoxia - Microcirculation · Endotoxemia $\cdot$ Rat $\cdot$ Kidney

\section{Introduction}

Molecular oxygen $\left(\mathrm{O}_{2}\right)$ has a central role in cellular respiration where it is used in the production of adenosine triphosphate (ATP); the main molecule supplying energy to metabolic processes for supporting cell and organ function [15]. The primary site of oxygen delivery from blood to organ cells is the microcirculation. Therefore, 
microcirculatory oxygenation is considered a parameter of key (patho)physiological importance [26, 28]. Hence, monitoring microcirculatory oxygenation under (patho)physiological conditions has been the focus of many studies, for example, to assess the severity of organ hypoxia during shock and to guide treatment strategies aimed at improving organ oxygenation [7]. Methods for quantitative assessment of microcirculatory oxygen tension $\left(\mathrm{pO}_{2}\right)$ include invasive techniques, such as oxygen electrodes [3, 32], and noninvasive techniques, such as phosphorimetry $[2,21,24,29$, $30,35]$.

Phosphorimetry is a non-invasive optical method for measuring oxygen tension quantitatively in vivo, based on oxygen-dependent quenching of phosphorescence of metallo-porphyrins, such as palladium porphyrin $[4,29,30]$. The phosphorescence decay trace is measured and fitted using a mono-exponential curve. The $\mathrm{pO}_{2}$ is calculated using the Stern-Volmer relationship, which directly relates the phosphorescence decay rate (or lifetime) [25]. Under (patho)physiological conditions, however, it has been well established that microvascular oxygenation could be spatially heterogeneously rather than homogenously distributed within the phosphorimetric measurement volume and that, within one organ, hypoxic tissue could co-exist with normoxic tissue [7, 36]. These hypoxic tissue fractions could potentially lead to organ dysfunction and therefore their detection is essential. Instead of mono-exponential curve fitting of the phosphorescence decay trace, providing a single $\mathrm{pO}_{2}$ value for the phosphorimetric measurement volume, multi-exponential curve fitting could be used for the analysis of the decay traces, which provides a distribution (or histogram) of $\mathrm{pO}_{2}$ values [11-13].

The fundamental method for multi-exponential curve fitting analysis of fluorescent and phosphorescent decay traces for recovering $\mathrm{pO}_{2}$ distributions is the exponential series method (ESM) [9]. An alternative analytical approach, the maximum entropy method (MEM) [16], was compared to the ESM and both methods were shown to be equally powerful in resolving underlying distributions, but since the ESM was significantly faster than the more complex MEM, ESM has been suggested as the method of choice [23]. Furthermore, the MEM was recently questioned as recovered $\mathrm{pO}_{2}$ distributions sometimes contained nonphysiologically high $\mathrm{pO}_{2}$ values. This was later attributed to the reduced accuracy of the MEM for high $\mathrm{pO}_{2}$ values due to noise [27, 33]. Vinogradov and Wilson have reported a deconvolution method that used similar algebraic methodology as in the ESM, but where function minimization was approached though the application of quadratic programming principles [31]. This method provided results similar to the ESM in a significantly reduced computation time. Refinement of the ESM was proposed by Golub et al. by transforming the measured decay traces using a heterogeneity factor, as introduced by Zheng et al., which accounts for the difference between decay traces obtained from continuous quencher concentration distributions (i.e., the measured decay trace) and the equivalent discrete distributions (i.e., the decay trace obtained from the $\mathrm{pO}_{2}$ histogram as described by the ESM) $[6,34]$.

Although it is generally accepted that the oxygenquenched phosphorescence and delayed fluorescence decay traces can be analyzed using multi-exponential curve fitting, its application until now has been limited to a few (patho)physiological studies, probably because the reliability of the recovered $\mathrm{pO}_{2}$ histograms has never been extensively evaluated and lacks documentation. The aim of the present study is to extensively evaluate the ability of multi-exponential fitting analysis to adequately determine $\mathrm{pO}_{2}$ histograms from simulated decay traces at different signal-to-noise ratios (SNRs). In the first part of the study, we tested whether the application of the heterogeneity factor as proposed by Golub et al. actually improves the recovery of $\mathrm{pO}_{2}$ histograms as this has never been shown; how noise affects the recovery of $\mathrm{pO}_{2}$ histograms; and whether the effects of noise could be suppressed by application of a median filter. However, the adverse effect of the heterogeneity factor is an amplification of both the signal and the noise at the end of the decay trace. Therefore, rather than transforming the phosphorescence decay trace using the heterogeneity factor and thereby amplifying the noise in the latter part of the trace, here, we included the heterogeneity factor in the fit model as a modified version of the method developed by Golub and Zheng et al. and applied by Mik and Johannes et al. [6, 19, 20, 34]. In the second part of this study, we applied multi-exponential curve fitting analysis for the recovery of bimodal $\mathrm{pO}_{2}$ distributions, with a hypoxic and a normoxic mode, at several SNRs and tested the ability of the analysis procedure to detect hypoxia. In the third part of the study, we applied multi-exponential curve fitting analysis for the recovery of microvascular $\mathrm{pO}_{2}$ histograms measured in the rat kidney in a model of endotoxemic shock and fluid resuscitation.

\section{Materials and methods}

\subsection{Generation of decay traces}

Analysis software for the simulation of $\mathrm{pO}_{2}$ distributions, conversion to decay traces, multi-exponential curve fitting analysis, and recovery $\mathrm{pO}_{2}$ histograms was written in LabView (version 8.6, National Instruments, Austin, TX, USA).

The continuous input $\mathrm{pO}_{2}[\mathrm{mmHg}]$ distributions simulated for this study were described by a single or double 
Gaussian function $f\left(\mathrm{pO}_{2}\right)$, where $f\left(\mathrm{pO}_{2}\right) \geq 0$ and $\sum f\left(\mathrm{pO}_{2}\right)=1$. The simulated $\mathrm{pO}_{2}$ distributions were subsequently converted to continuous decay rate $\left[k\left(\mu \mathrm{s}^{-1}\right)\right]$ distributions via the Stern-Volmer equation: $k\left(\mathrm{pO}_{2}\right)=$ $k_{0}+k_{q} \cdot \mathrm{pO}_{2}$ [25]. Here, $k_{0}\left(\mu \mathrm{s}^{-1}\right)$ and $k_{q}\left(\mu \mathrm{s}^{-1} \mathrm{mmHg}^{-1}\right)$ are the phosphor-dependent decay rate at $\mathrm{pO}_{2}=0 \mathrm{mmHg}$ and quenching constant, respectively. Decay traces $P(t)$ were obtained by substitution of the $\mathrm{pO}_{2}$ distributions into:

$P(t)=\int f\left(\mathrm{pO}_{2}\right) e^{-\left(k_{0}+k_{q} \cdot \mathrm{pO}_{2}\right) \cdot t} \mathrm{dpO}_{2}$

To the decay traces, having an amplitude of 1 at $t=0$ as described by the Gaussian function, variable uniform white noise (representing mainly thermal noise) was added to set the SNR (defined as the maximum phosphorescence amplitude/peak-to-peak noise) from 100 to 10, representing SNRs typically found in experiments (a typical decay trace is presented in Figs. 1b, 5a).

\subsection{Multi-exponential curve fitting}

The generated decay traces, corresponding to continuous $\mathrm{pO}_{2}$ distributions, were analyzed by multi-exponential curve fitting using a constrained Levenberg-Marquardt procedure, a procedure which minimizes the weighted sum of the squared residuals (i.e., data-fit) $\chi^{2}$. Multi-exponential fitting was performed by standard fitting of a sum of exponentials to the decay trace (i.e., the ESM) [9].

In the ESM, the decay trace is fitted by a sum of $N$ exponentials with fixed, uniformly spaced decay rates, $k_{i}\left(\mathrm{pO}_{2}\right)$, and variable pre-exponential fraction coefficients, $f_{i}\left(\mathrm{pO}_{2}\right)$, which are to be recovered. The histogram bins have a width of $2 \delta \mathrm{mmHg}$ and are centered on $\mathrm{pO}_{2}=\delta+$ $2 \mathrm{i} \delta \mathrm{mmHg}$, where $i=0,1, \ldots N-1$ :

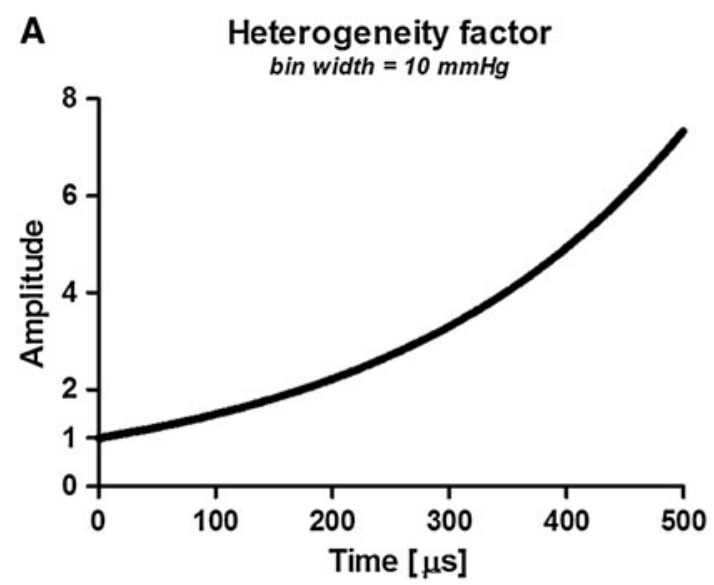

$P(t)=\sum_{i=0}^{N-1} f_{i}(\delta+2 i \delta) e^{-\left[k_{0}+k_{q} \cdot(\delta+2 i \delta)\right] \cdot t}$

Equation 2 does not take into account the difference between decay traces obtained from continuous quencher concentration distributions (i.e., the measured decay trace Eq. 1) and the equivalent discrete distributions (i.e., the decay trace obtained from the $\mathrm{pO}_{2}$ histogram as described by the ESM). To correct for this issue, Golub and Zheng et al. proposed to multiply the decay traces with a timedependent heterogeneity factor [6, 34]:

$P(t)^{*}=P(t)\left[\frac{e^{k_{0} t} k_{q} \delta t}{\sinh \left(k_{q} \delta t\right)}\right]=\sum_{i=0}^{N-1} f_{i}(\delta+2 i \delta) e^{-k_{q} \cdot(\delta+2 i \delta) \cdot t}$

However, the heterogeneity factor amplifies both the signal and the noise at the end of the decay trace, and therefore, in this study, rather than transforming the phosphorescence decay trace using the heterogeneity factor we included the heterogeneity factor in the fit model and thereby prevented amplification of the noise in the latter part of the trace (Fig. 1). The fit model is then described by:

$P(t)=\left[\frac{\sinh \left(k_{q} \delta t\right)}{e^{k_{0} t} k_{q} \delta t}\right] \sum_{i=0}^{N-1} f_{i}(\delta+2 i \delta) e^{-k_{q} \cdot(\delta+2 i \delta) \cdot t}$

\subsection{Simulations}

In this study, the decay trace according to Eq. 1 is simulated with a $\mathrm{pO}_{2}$ range from 0 to $300 \mathrm{mmHg}$ with a resolution of $1 \mathrm{mmHg}$. Simulated sampling rate was set to $1 \mathrm{MHz}$ (1 sample/ $/ \mu \mathrm{s}) . \quad k_{0}$ and $k_{\mathrm{q}}$ were $1 / 251$ and $273 \mu \mathrm{s}^{-1}$ $\mathrm{mmHg}^{-1}$, respectively. Measurement time was set to $2 / k_{0}$, i.e., $502 \mu$ s. These values correspond to values previously
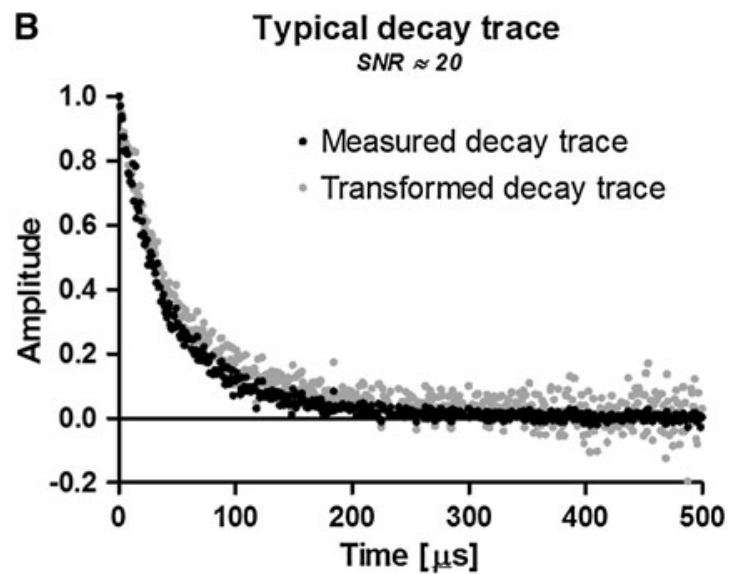

Fig. 1 a The heterogeneity factor as described by Golub et al. [5] for transformation of the measured decay trace. b A typically measured decay trace (black), having a signal-to-noise ratio (SNR) of $\sim 20$, and the corresponding transformed decay trace (gray) 
found for the applied phosphorimeter and phosphorescent dye as described below.

Tolerance for $\chi^{2}$ for the fit optimization was $10^{-3}$. The initial fit coefficients were set at $f_{i}=1 / N$, where $N$ is the number of bins in the $\mathrm{pO}_{2}$ histogram, so that the sum of all fraction coefficients equals 1 . As a constraint, the fraction coefficients were not allowed to be scaled below 0 . The histogram bin width was set to $10 \mathrm{mmHg}(\delta=5)$ and the histogram $\mathrm{pO}_{2}$ range was set from 0 to $150 \mathrm{mmHg}$ $(N=15)$.

In the first set of simulations, we tested whether the application of a noise-reducing median filter or the heterogeneity factor to the ESM would actually improve the recovery of $\mathrm{pO}_{2}$ histograms from (noisy) decay traces, having an SNR of 100 and 10. In the second set of simulations we applied the ESM for the recovery of bimodal $\mathrm{pO}_{2}$ distributions, with a hypoxic and a normoxic mode at different ratios, at several SNRs and tested the ability of the analysis procedure to detect hypoxia.

\subsection{Data analysis}

Data plotting was performed in GraphPad Prism (GraphPad Software, La Jolla, CA, USA). To allow clear visual comparison of $\mathrm{pO}_{2}$ distributions recovered using the different analytical approaches, the mean $+\mathrm{SD}$ values in the $\mathrm{pO}_{2}$ distributions ( $n=50$ runs per simulation) were plotted and connected with lines. In the first set of simulations, the recovered $\mathrm{pO}_{2}$ histograms were compared to the input distributions using the Kolmogorov-Smirnov test, similarly to Golub et al. [6]. The $D$ value provided by this test was used to lookup a corresponding $P$ value (also depending on the number of histogram bins), where $P>0.05$ indicates that the input and recovered histograms are not significantly different (i.e., are similar). In the second set of simulations, the fraction of the first bin of the recovered $\mathrm{pO}_{2}$ histograms was plotted versus the simulated degree of hypoxia and analyzed using linear regression analysis to evaluate the adequacy of the detection of hypoxia in bimodal $\mathrm{pO}_{2}$ distributions.

\subsection{In vivo experiment}

To demonstrate the (patho)physiological relevance of multi-exponential curve fitting analysis of in vivo obtained phosphorescence decay traces for recovering microvascular $\mathrm{pO}_{2}$ histograms, measurements were performed in the rat kidney $(n=5)$ at baseline, during endotoxemic shock, and after fluid resuscitation. The protocol for this experiment has been approved by the animal ethics committee of the Academic Medical Center at the University of Amsterdam and has been described elsewhere [11].
Rats were anesthetized with an intraperitoneal injection of $90 \mathrm{mg} / \mathrm{kg}$ ketamine (Nimatek ${ }^{\circledR}$; Eurovet, Bladel, the Netherlands), $0.25 \mathrm{mg} / \mathrm{kg}$ medetomidine (Domitor; Pfizer, New York, NY, USA) and $0.05 \mathrm{mg} / \mathrm{kg}$ atropine-sulfate (Centrafarm, Etten-Leur, the Netherlands). After tracheotomy the animals were mechanically ventilated with a $\mathrm{FiO}_{2}$ of 0.4. Body temperature was maintained at $37.0 \pm 0.5^{\circ} \mathrm{C}$ by external warming. The ventilator settings were adjusted to maintain an arterial $\mathrm{pCO}_{2}$ between 35 and $40 \mathrm{mmHg}$. A polyethylene catheter (outer diameter $=0.9 \mathrm{~mm}$; Braun, Melsungen, Germany) was placed in the right carotid artery to monitor arterial blood pressure and heart rate.

The left kidney was decapsulated and immobilized in a Lucite kidney cup (K. Effenberger, Pfaffingen, Germany) via a $\sim 4 \mathrm{~cm}$ incision of the left flank. The phosphorescent dye (Oxyphor G2, $\lambda_{\text {excitation }}=\sim 440 \mathrm{~nm}, \lambda_{\text {emission }}=$ $\sim 800 \mathrm{~nm}$; Oxygen Enterprises, Philadelphia, PA, USA) was subsequently infused $(6 \mathrm{mg} / \mathrm{kg})$ intravenously for $5 \mathrm{~min}$, followed by $30 \mathrm{~min}$ stabilization time [4]. The blue ( $\sim 40 \mathrm{~nm}$ ) excitation of Oxyphor G2 allows assessment of microvascular $\mathrm{pO}_{2}$ in the renal cortex, in which it has been shown that hypoxic areas might arise during endotoxemia $[11,12]$.

The applied phosphorimeter and phosphorescent dye have been described elsewhere [10, 14]. Briefly, phosphorimetric sampling rate was set to $1 \mathrm{MHz}$ (1 sample/ $\mu \mathrm{s})$. $k_{0}$ and $k_{q}$ were $1 / 251$ and $273 \mu \mathrm{s}^{-1} \mathrm{mmHg}^{-1}$, respectively, corresponding to the constants previously found for Oxyphor G2 [10]. Phosphorimetric measurement time was set to $2 / k_{0}$, i.e., $502 \mu \mathrm{s}$.

Endotoxemic shock was induced by infusion of a bolus of lipopolysaccharide (LPS, $10 \mathrm{mg} / \mathrm{kg}$, serotype 0127:B8, Sigma-Aldrich, St. Louis, MO, USA). When mean arterial pressure decreased to $40 \mathrm{mmHg}$, fluid resuscitation was started using a hydroxyethyl starch (HES) solution $(5 \mathrm{ml} / \mathrm{kg}$ followed by $5 \mathrm{ml} / \mathrm{kg} / \mathrm{h}$; Voluven, 6\% HES 130/0.4; Fresenius Kabi, Schelle, Belgium). During the entire protocol, heart rate, mean arterial pressure, end-tidal $\mathrm{pCO}_{2}$, and rectal temperature were monitored continuously. Microvascular $\mathrm{pO}_{2}$ was assessed every $10 \mathrm{~s}$ in the same renal phosphorimetric measurement volume (thus no spatial information) and microvascular $\mathrm{pO}_{2}$ histograms were recovered at baseline, during endotoxemic shock (LPS), and after $2 \mathrm{~h}$ of fluid resuscitation (LPS + HES).

\section{Results}

In the first set of simulations, we tested whether the application of a median filter or heterogeneity factor to the ESM would improve the recovery of $\mathrm{pO}_{2}$ histograms from noisy decay traces, having an SNR of 100 and 10. Simulated decay traces and corresponding histograms at a 


\section{Exponential Series Method}

A

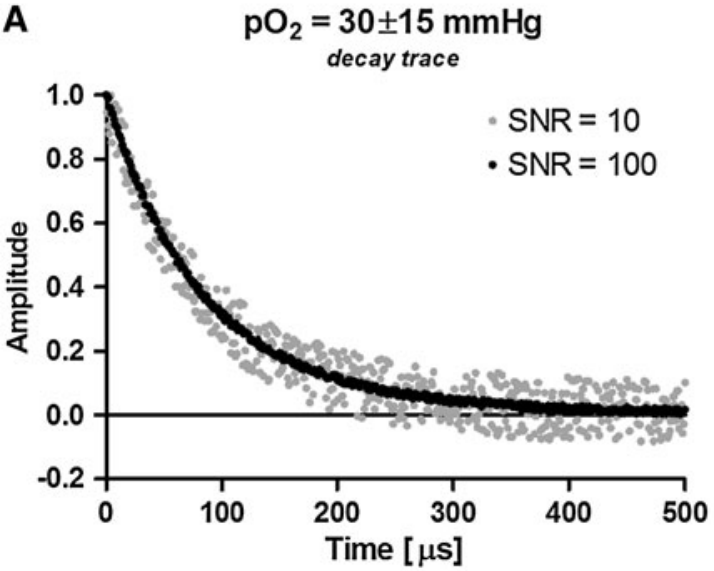

C

$\mathrm{pO}_{2}=90 \pm 15 \mathrm{mmHg}$

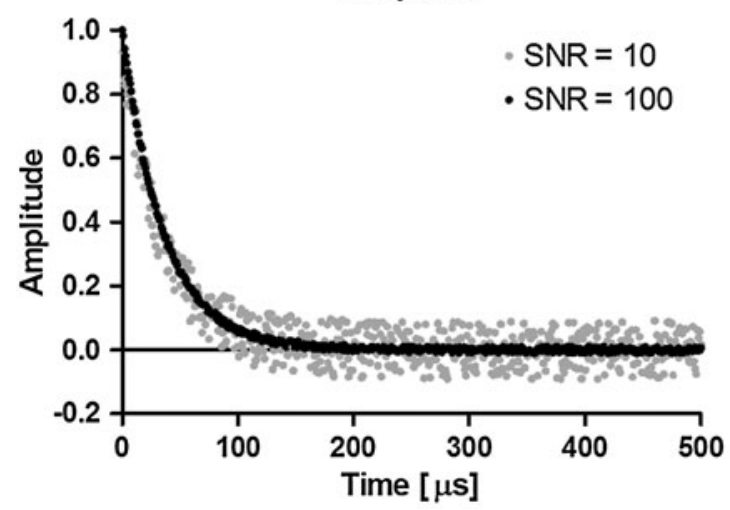

B
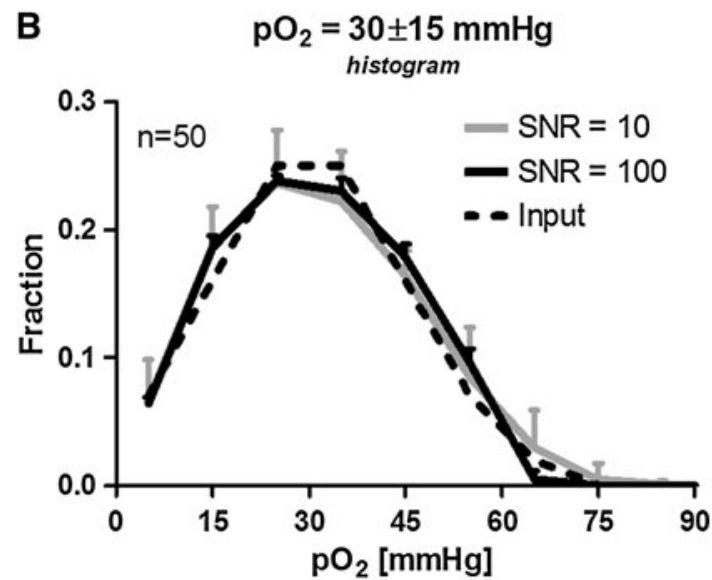

D

$$
\mathrm{pO}_{2}=90 \pm 15 \mathrm{mmHg}
$$

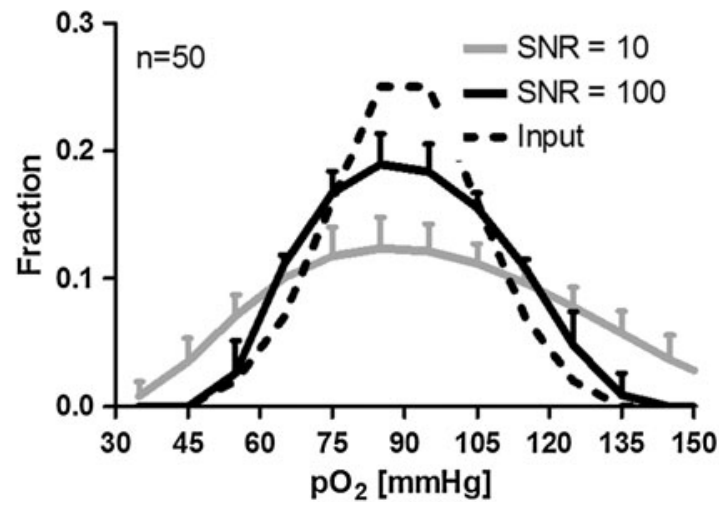

Fig. 2 Decay traces and corresponding histograms at a mean \pm SD oxygen tension $\left(\mathrm{pO}_{2}\right)$ of $30 \pm 15$ and $90 \pm 15 \mathrm{mmHg}$ at $\mathrm{SNRs}$ of 100 and 10. The input $\mathrm{pO}_{2}$ distributions are depicted by the black dashed line. The histograms are recovered using the exponential series method

mean $\pm \mathrm{SD} \mathrm{pO}_{2}$ of $30 \pm 15$ and $90 \pm 15 \mathrm{mmHg}$ at $\mathrm{SNRs}$ of 100 and 10 are shown in Figs. 2, 3, 4. Noise does not affect the recovery of $\mathrm{pO}_{2}$ histograms with a low mean $\mathrm{pO}_{2}$ and widens the $\mathrm{pO}_{2}$ histograms with a high mean $\mathrm{pO}_{2}$, which could not be prevented with a median filter. All three methods adequately recover the input $\mathrm{pO}_{2}$ distributions both at high and low SNRs, i.e., input and recovered histograms are not significantly different $(P>0.05)$ as shown in Table 1. Overall, application of a median filter (Fig. 3) or heterogeneity factor (Fig. 4) to the ESM (Fig. 2) does not seem to improve the recovery of the histograms. Therefore, for future histogram analysis, no filter or heterogeneity factor will be applied.

In the second set of simulations, we applied the ESM for the recovery of bimodal $\mathrm{pO}_{2}$ distributions, with a hypoxic and a normoxic mode at different ratios, at several SNRs and tested the ability of the analysis procedure to detect the extent of hypoxia. In Fig. 5, it is shown that, at high SNRs, the multi-exponential curve fitting analysis procedure adequately recovers bimodal distributions. As the noise level increases, the distinction between the two modes diminishes. However, the fraction of the first histogram bin remains linearly related to the degree of hypoxia (Fig. 5d), even at low SNRs.

To demonstrate the (patho)physiological relevance of multi-exponential curve fitting analysis of in vivo obtained phosphorescence decay traces for recovering microvascular $\mathrm{pO}_{2}$ histograms, measurements were performed in the rat kidney before and during endotoxemia. A typical baseline decay trace, having a SNR of $18(=1 / 0.056)$, is depicted in Fig. $6 \mathrm{a}$ and the microvascular $\mathrm{pO}_{2}$ histograms at baseline, after induction of endotoxemia (LPS), and $2 \mathrm{~h}$ after the start of fluid resuscitation (LPS + HES) are shown in Fig. 6b. Mean microvascular oxygen tension, $\left\langle\mathrm{pO}_{2}\right\rangle$, obtained from the histograms was $93 \pm 14 \mathrm{mmHg}$ at baseline and decreased to $67 \pm 13 \mathrm{mmHg}$ after induction of endotoxemia. After $2 \mathrm{~h}$ of fluid resuscitation, $\left\langle\mathrm{pO}_{2}\right\rangle$ remained low at $64 \pm 13 \mathrm{mmHg}$, but the hypoxic peak that had arisen during endotoxemia was reduced. Using monoexponential curve fitting analysis the following values were 


\section{ESM with median filter}
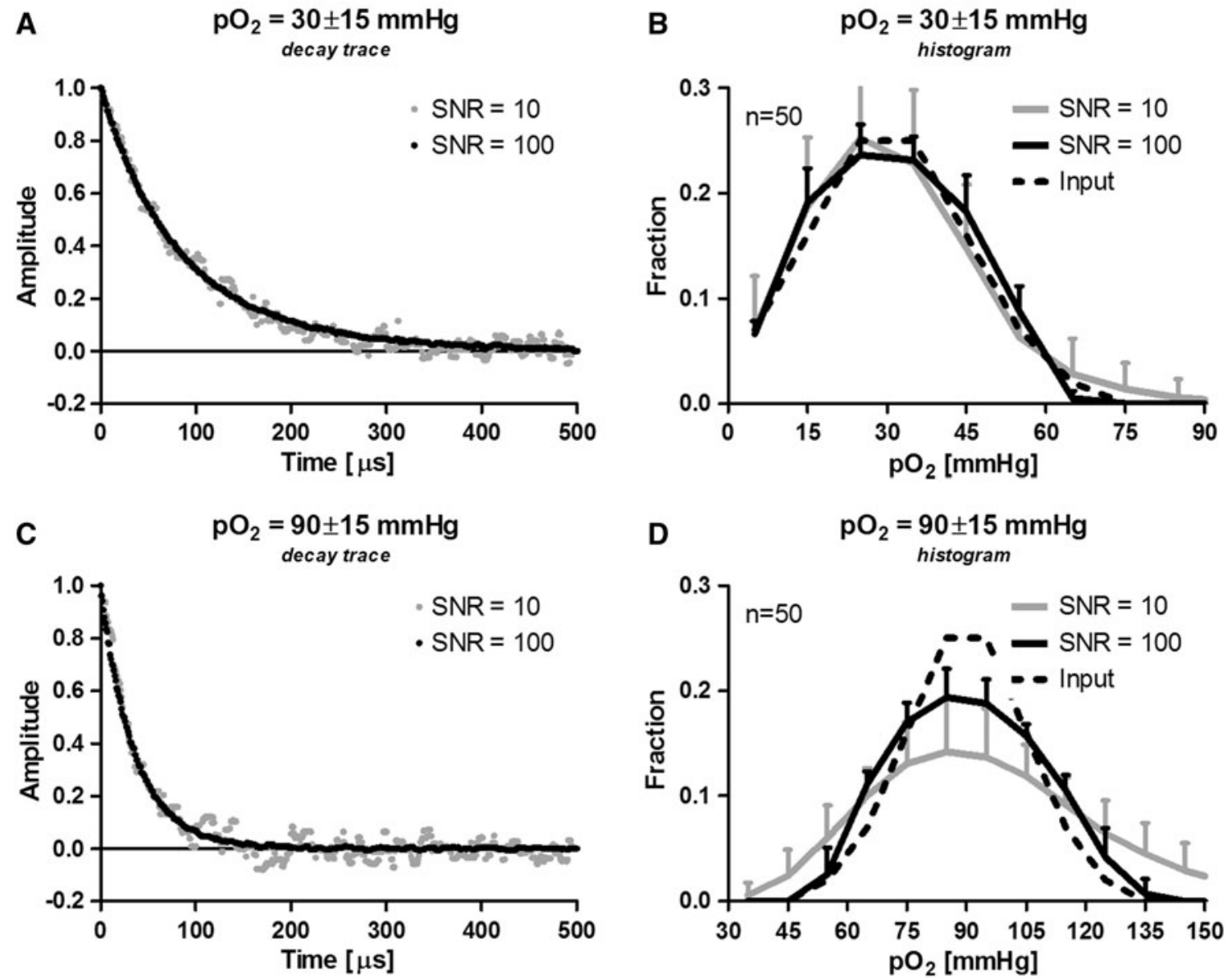

Fig. 3 Decay traces and corresponding histograms at a mean $\pm \mathrm{SD}$ oxygen tension $\left(\mathrm{pO}_{2}\right)$ of $30 \pm 15$ and $90 \pm 15 \mathrm{mmHg}$ at SNRs of 100 and 10. The input $\mathrm{pO}_{2}$ distributions are depicted by the black dashed

line. The histograms are recovered using the exponential series method (ESM) with filtered decay traces

obtained for microvascular $\mathrm{pO}_{2}: 82 \pm 19 \mathrm{mmHg}$ at baseline, $46 \pm 17 \mathrm{mmHg}$ after induction of endotoxemia, and $47 \pm 8$ after $2 \mathrm{~h}$ of fluid resuscitation. Figure $6 \mathrm{~b}$, in combination with the results obtained by mono-exponential curve fitting analysis, illustrates the importance of recovering $\mathrm{pO}_{2}$ histograms under (patho)physiological conditions. The redistribution of oxygen by the treatment of endotoxemia with fluid resuscitation can be monitored and potentially provides insight into the nature of the renal insult caused by endotoxemia and the efficacy of its treatment with fluid resuscitation.

\section{Discussion and conclusions}

The aim of this study was to extensively evaluate the ability of multi-exponential fitting analysis to adequately determine $\mathrm{pO}_{2}$ histograms from phosphorescence decay traces at different SNRs. For this purpose, we simulated decay traces

representing uni- and bimodal $\mathrm{pO}_{2}$ distributions and recovered the $\mathrm{pO}_{2}$ histograms using (1) the ESM, (2) the ESM with filtered decay trace, and (3) the ESM with heterogeneity factor at several SNRs. Application of a median filter or heterogeneity factor to the ESM did not improve the recovery of the $\mathrm{pO}_{2}$ histograms. Ultimately, we applied the ESM for the recovery of microvascular $\mathrm{pO}_{2}$ histograms measured in the rat kidney in a model of endotoxemic shock and fluid resuscitation to demonstrate the (patho)physiological relevance of multi-exponential curve fitting analysis of in vivo obtained phosphorescence decay traces. We showed that the mean microvascular oxygen tension, $\left\langle\mathrm{pO}_{2}\right\rangle$, decreased after induction of endotoxemia and that after $2 \mathrm{~h}$ of fluid resuscitation, $\left\langle\mathrm{pO}_{2}\right\rangle$ remained low, but the hypoxic peak that had arisen during endotoxemia was reduced. This finding illustrates the importance of recovering $\mathrm{pO}_{2}$ histograms under (patho)physiological conditions as the redistribution of oxygen by the treatment of endotoxemia with fluid resuscitation can be monitored and potentially provides 
ESM with heterogeneity factor
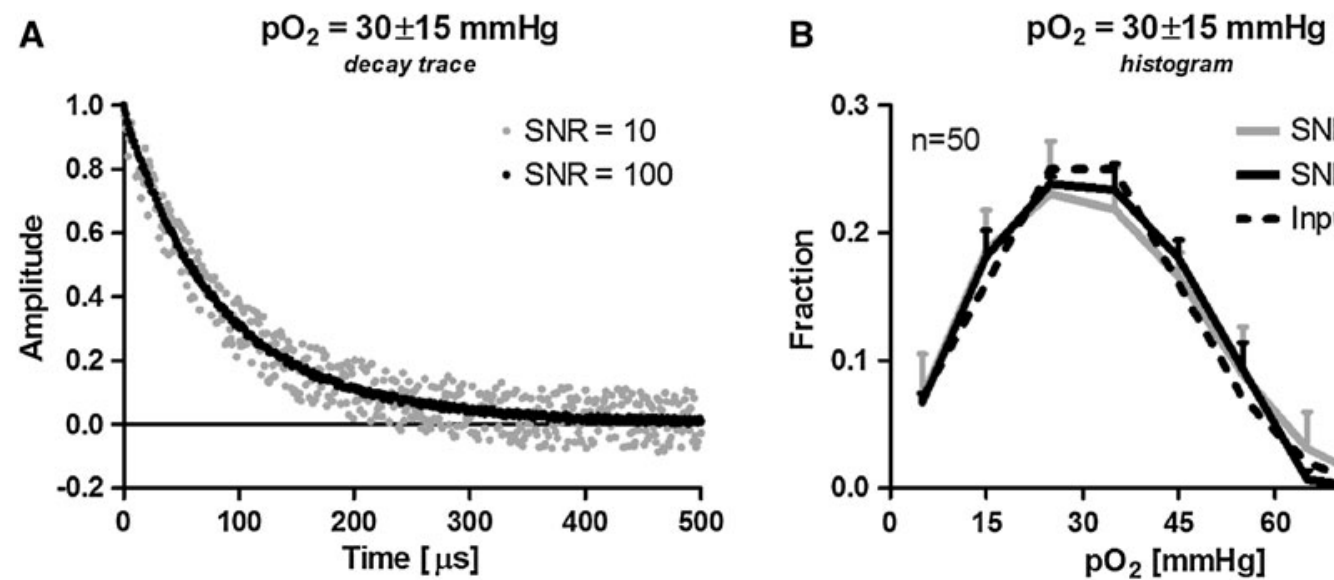

C
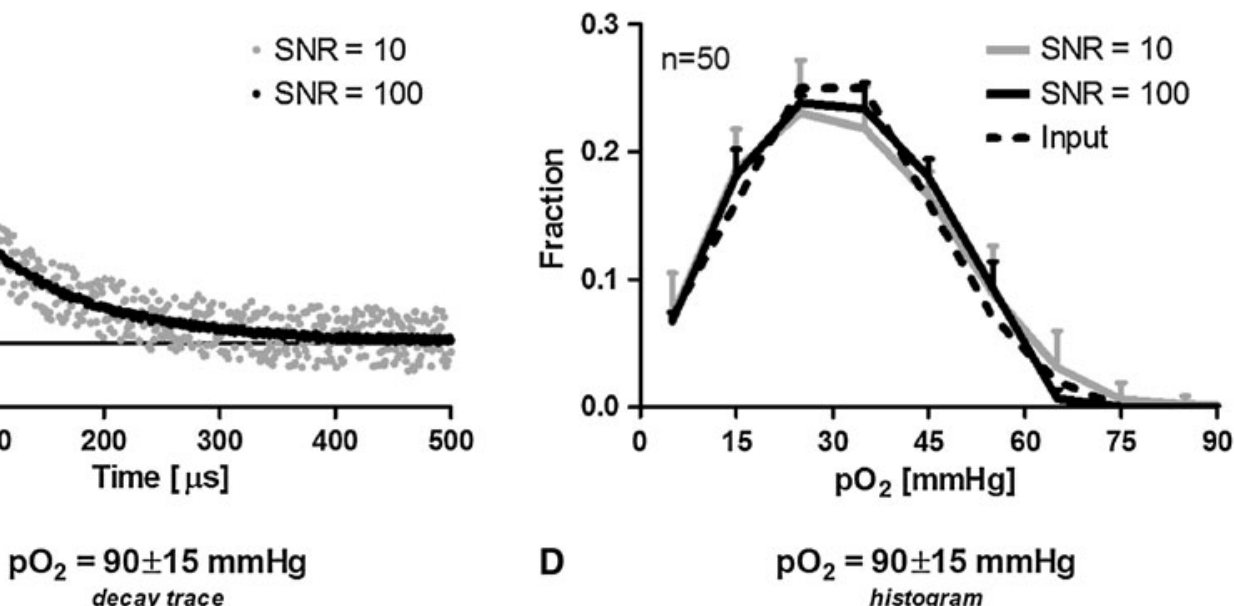

decay trace

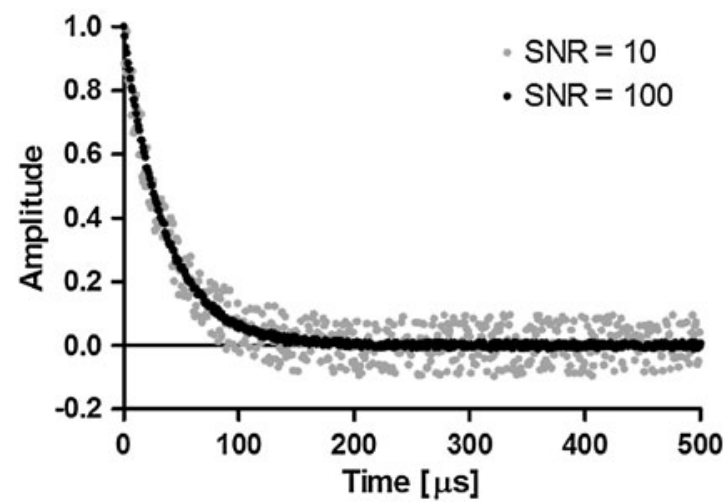

D

$$
\mathrm{pO}_{2}=\underset{\text { histogram }}{90 \pm 15 \mathrm{mmHg}}
$$

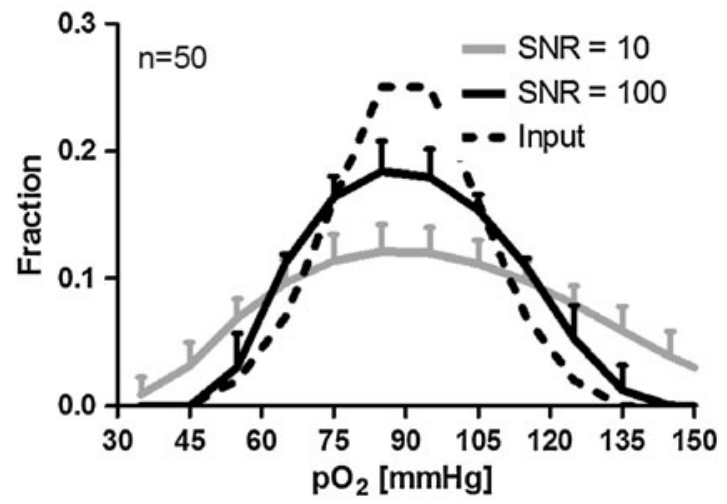

Fig. 4 Decay traces and corresponding histograms at a mean \pm SD oxygen tension $\left(\mathrm{pO}_{2}\right)$ of $30 \pm 15$ and $90 \pm 15 \mathrm{mmHg}$ at $\mathrm{SNRs}$ of 100 and 10 . The input $\mathrm{pO}_{2}$ distributions are depicted by the black dashed

Table 1 Kolmogorov-Smirnov test results ( $D$ values) comparing input and recovered oxygen tension $\left(\mathrm{pO}_{2}\right)$ histograms

\begin{tabular}{lllll}
\hline $\mathrm{pO}_{2}$ & \multicolumn{2}{l}{$30 \pm 15 \mathrm{mmHg}$} & \multicolumn{2}{l}{$90 \pm 15 \mathrm{mmHg}$} \\
\hline $\mathrm{SNR}$ & 100 & 10 & 100 & 10 \\
$\mathrm{ESM}$ & 0.2545 & 0.2727 & 0.2035 & 0.2468 \\
FLTR & 0.2593 & 0.2765 & 0.2507 & 0.2391 \\
$\mathrm{HET}$ & 0.2532 & 0.2729 & 0.2632 & 0.2161 \\
\hline
\end{tabular}

For 15-bin histograms, $P>0.05$ if $D<0.3040$

$\mathrm{pO}_{2}$ oxygen tension, $S N R$ signal-to-noise ratio, ESM exponential series method, FLTR ESM with median filter, HET ESM with heterogeneity factor

insight into the nature of the renal insult caused by endotoxemia and the efficacy of its treatment with fluid resuscitation [11-13].

The (patho)physiological relevance of tissue $\mathrm{pO}_{2}$ heterogeneities has been appreciated for decades [36]. Oxygen electrodes have been extensively used to measure tissue line. The histograms are recovered using the exponential series method (ESM) with the heterogeneity factor

$\mathrm{pO}_{2}$ at different sites and depths within organs to recover $\mathrm{pO}_{2}$ profiles $[1,17,18,22]$. However, since oxygen electrode measurements are confined to a small tissue volume, only very superficial tissue oxygenation can be assessed noninvasively [32]. Mapping tissue oxygenation in depth requires insertion of one or more electrodes into the organ, causing cell damage and bleeding, which severely limits the applicability of this technique. The introduction of phosphorimetry [29, 30], in contrast, has opened the field of non-invasive and online monitoring of microcirculatory oxygenation and has initiated numerous studies investigating the (patho)physiological mechanisms underlying several types of shock [8] and the effects of different treatment strategies [e.g., 11-13].

It is well established that endotoxemia-induced microvascular oxygenation heterogeneities have a key role in the development of numerous clinical complications, including renal failure [7, 11-14]. However, although it is generally accepted that the oxygen-quenched phosphorescence and 

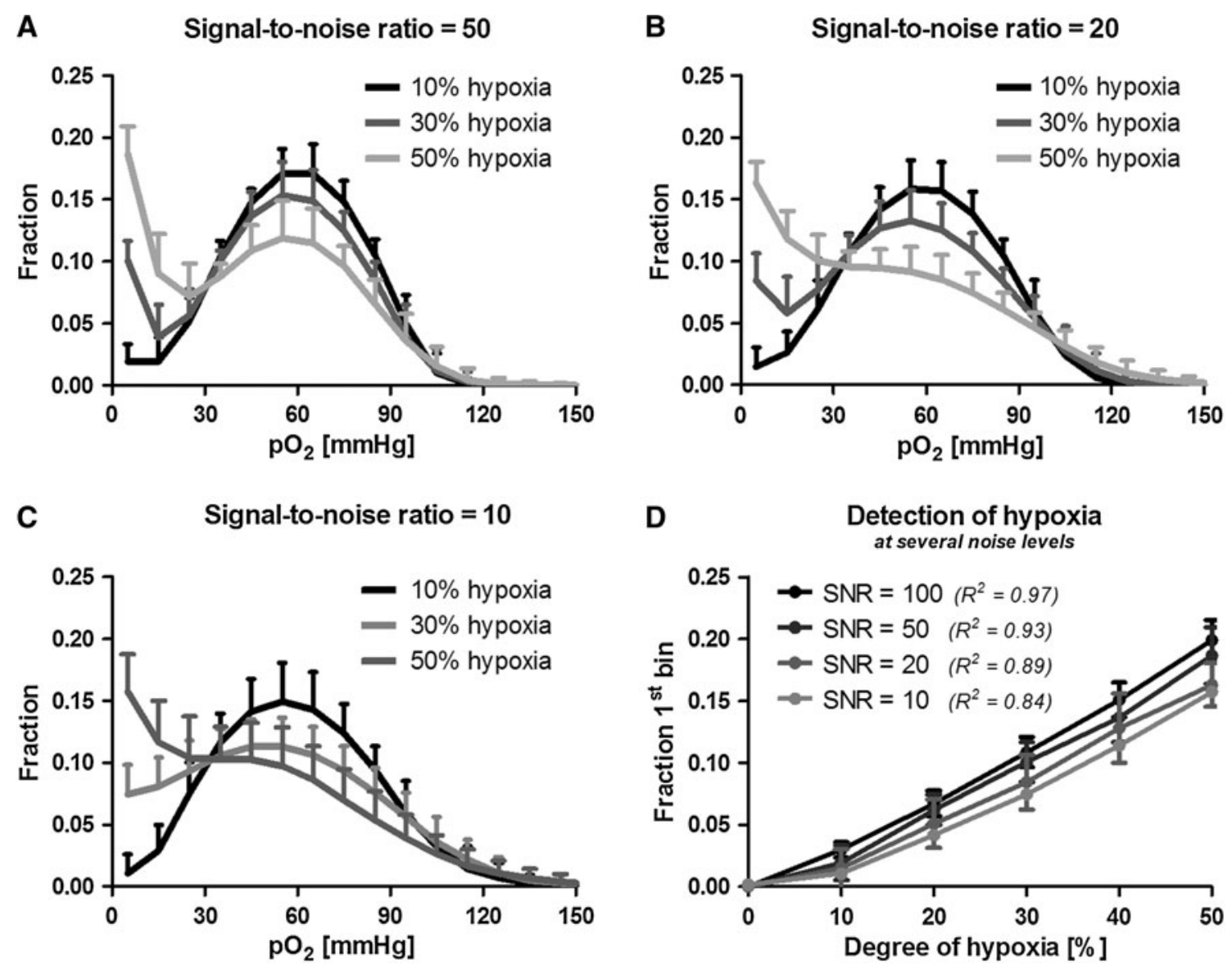

Fig. 5 Bimodal histograms with a hypoxic $(0 \pm 15 \mathrm{mmHg})$ and a normoxic $(60 \pm 15 \mathrm{mmHg})$ mode $(\mathbf{a}-\mathbf{c})$. The contribution of the hypoxic mode was 10,30 , or $50 \%$ with signal-to-noise ratios (SNRs)

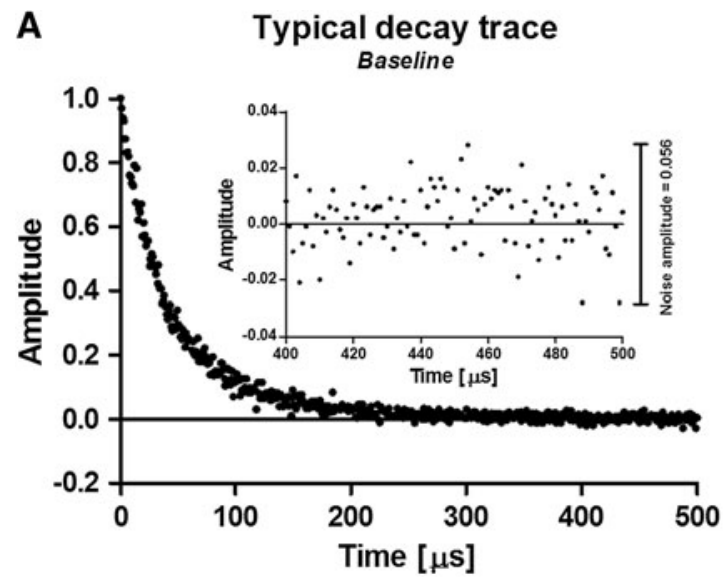

Fig. 6 a A typical baseline decay trace, having a signal-to-noise ratio of $18(=1 / 0.056)$. b Microvascular oxygen tension histograms at baseline, after induction of endotoxemia (LPS), and $2 \mathrm{~h}$ after the start of fluid resuscitation (LPS + HES). Mean microvascular oxygen

delayed fluorescence decay traces can be analyzed using multi-exponential curve fitting, only a few (patho)physiological studies have applied this methodology for the assessment of these critical oxygenation heterogeneities. of $50(\mathbf{a}), 20$ (b), or $10(\mathbf{c})$. In d, it is shown that the fraction of the first histogram bin is linearly related to the degree of hypoxia

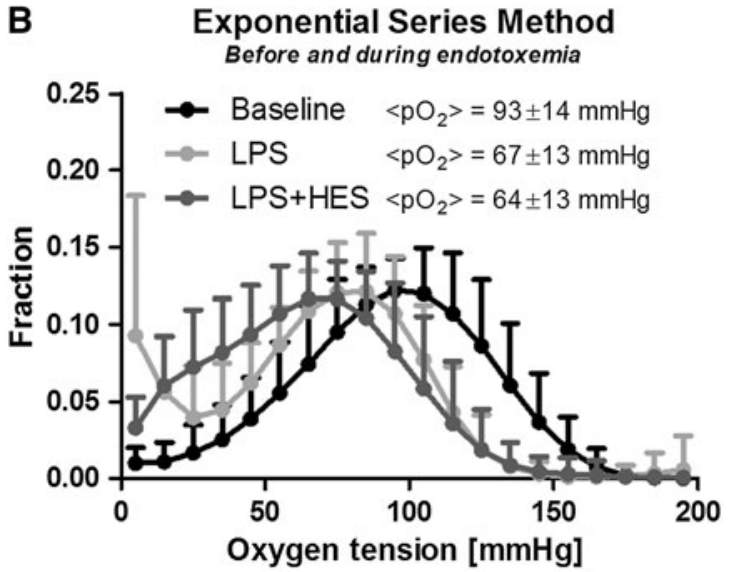

tension, $\left\langle\mathrm{pO}_{2}\right\rangle$, was $93 \pm 14 \mathrm{mmHg}$ at baseline and decreased to $67 \pm 13 \mathrm{mmHg}$ after induction of endotoxemia. After $2 \mathrm{~h}$ of fluid resuscitation, $\left\langle\mathrm{pO}_{2}\right\rangle$ remained low at $64 \pm 13 \mathrm{mmHg}$, but the hypoxic peak that had arisen during endotoxemia was reduced

This is probably because the reliability of the recovered $\mathrm{pO}_{2}$ histograms had never been extensively evaluated and lacked documentation. As the golden standard for measuring $\mathrm{pO}_{2}$ in vivo (i.e., the oxygen electrode) is unable to 
measure the $\mathrm{pO}_{2}$ heterogeneity, proper validation of multiexponential curve fitting analysis, by comparison to this golden standard, is impossible. Hence, evaluating the reliability of this method can only be done using simulations.

With the introduction of the heterogeneity factor for the recovery of $\mathrm{pO}_{2}$ histograms by Golub et al. [6], the method was applied for recovering one Gaussian $\mathrm{pO}_{2}$ distribution at several SNRs. However, the ability of the ESM (with and without the heterogeneity factor) to recover $\mathrm{pO}_{2}$ histograms under noisy conditions depends on the $\mathrm{pO}_{2}$ distribution; low- $\mathrm{pO}_{2}$ distributions can be recovered adequately even under low SNRs, but high- $\mathrm{pO}_{2}$ distributions require relatively high SNRs. As the phosphorescence decay rate constant $k\left(\mu \mathrm{s}^{-1}\right)$ is linearly related to the $\mathrm{pO}_{2}$, the number of data points above noise level, and thus fitting residuals, is inversely related to the $\mathrm{pO}_{2}$ and since the Levenberg-Marquardt procedure minimizes the sum of the squared residuals $\chi^{2}$ over the total extent of the decay trace. Thus, the relative contribution of the higher $\mathrm{pO}_{2}$ values to the fit is less than that of the lower $\mathrm{pO}_{2}$ values and therefore, noise affects the recovery of high $\mathrm{pO}_{2}$ values more than that of low $\mathrm{pO}_{2}$ values. A more extensive evaluation of this method, with both low and high $\mathrm{pO}_{2}$ distributions, was therefore required for determining its reliability.

Mik et al. [19] have performed such an evaluation of the ESM with heterogeneity factor and found that this method is indeed capable of recovering uni- and bimodal $\mathrm{pO}_{2}$ distributions for several SNRs. However, in that study the authors applied the heterogeneity factor as described by Golub et al. [6] and thereby amplified the noise at the end of the decay traces. Here, we present a modified version of the heterogeneity correction as developed by Golub and Zheng et al. and applied by Mik and Johannes et al. [6, 19, 20, 34]. Rather than transforming the phosphorescence decay trace using the heterogeneity factor, amplifying the noise in the latter part of the trace, we included the heterogeneity factor in the fit model. However, even though the noise was not amplified, in practice, the heterogeneity correction did not improve the recovery of $\mathrm{pO}_{2}$ histograms and was therefore omitted in the subsequent analyses. Furthermore, in attempt to reduce the influence of noise on the recovery of $\mathrm{pO}_{2}$ histograms, a median filter was applied. It should be noted, though, that application of a mean or median filter on noisy non-linear decay traces slightly 'stretches' the traces and thereby lowers the corresponding decay rates and thus $\mathrm{pO}_{2}$ values. As this 'stretching' property is stronger for the mean filter than for the median filter, we applied the latter (although this type of filter is usually applied to reduce the influence of outliers). However, application the median filter did not improve nor affect the recovery of $\mathrm{pO}_{2}$ histograms.

Some alternative methods are available for the recovery of $\mathrm{pO}_{2}$ histograms from phosphorescence and delayed fluorescence decay traces, each having specific advantages and disadvantages. The MEM, for instance, allows the recovery of very detailed histograms (typically 200 bins), but requires very high SNRs for stable operation (typically $>100$ ) [16]. In our phosphorimetry setup, however, the measured phosphorescence decay traces typically have a SNR of $\sim 20$. Both the study of Golub et al. and that of Mik et al., have shown that the ESM operates stable at modest SNRs (i.e., $\sim 20$ ), but at the expense of reduced histogram detail [6, 19]. Recently, the MEM was questioned by $\mathrm{Tsai}$ et al. since the recovered $\mathrm{pO}_{2}$ distributions contained nonphysiologically high $\mathrm{pO}_{2}$ values, but this was later attributed to the reduced accuracy of the MEM for high $\mathrm{pO}_{2}$ values due to noise [27, 33]. Furthermore, in a study by Siemiarczuk et al., the ESM was compared to the MEM and was found to be significantly faster than the MEM [23]. The high temporal resolution of the ESM (in the order of seconds) is clearly advantageous as it allows rapid assessment of $\mathrm{pO}_{2}$ histograms online.

Recently, multi-exponential curve fitting analysis of oxygen-quenched phosphorescence decay traces, in combination with the Stern-Volmer equation, has been applied in several studies investigating microvascular and interstitial $\mathrm{pO}_{2}$ distributions in healthy and diseased tissue. Johannes et al. were able to identify the presence of 'occult' hypoxic microvascular areas during shock that would not have been detected when applying mono-exponential curve fitting analysis [11, 12]. This study supports these findings by showing that the detection of hypoxia with the ESM is highly adequate, even for very low SNRs. Golub and Pittman, moreover, studied cross-sectional $\mathrm{pO}_{2}$ profiles in microvasculature and found a bimodal distribution that was interpreted to arise from two separate physiological compartments within the phosphorimetric measurement volume, i.e., the intra- and extravascular space [5]. Using similar methodology, Mik et al. have explored $\mathrm{pO}_{2}$ heterogeneities in liver and heart mitochondria using multi-exponential curve fitting analysis of oxygen-quenched delayed fluorescence of intramitochondrial protoporphyrin IX [19, 20]. These studies underscore the (patho)physiological relevance of $\mathrm{pO}_{2}$ histograms and support their use in future research.

In conclusion, this study has characterized how noise affects the recovery of $\mathrm{pO}_{2}$ histograms using the ESM and documented the reliability of the ESM for recovering both low- and high- $\mathrm{pO}_{2}$ distributions for SNRs typically found in the experimental setting. This study might therefore serve as a frame of reference for investigations focused on oxygen (re)distribution during health and disease and encourage researchers to (re-)analyze data obtained in (earlier) studies possibly revealing new insights into complex disease states and treatment strategies. Moreover, now that the reliability of the ESM has been documented, new investigations 
focused on studying $\mathrm{pO}_{2}$ distributions under numerous (patho)physiological conditions could be initiated.

Open Access This article is distributed under the terms of the Creative Commons Attribution Noncommercial License which permits any noncommercial use, distribution, and reproduction in any medium, provided the original author(s) and source are credited.

\section{References}

1. Baumgartl H, Leichtweiss HP, Lubbers DW, Weiss C, Huland H (1972) The oxygen supply of the dog kidney: measurements of intrarenal $\mathrm{PO}_{2}$. Microvasc Res 4:247-257

2. Buerk DG, Tsai AG, Intaglietta M, Johnson PC (1998) Comparing tissue $\mathrm{PO}_{2}$ measurements by recessed microelectrode and phosphorescence quenching. Adv Exp Med Biol 454:367-374

3. Clark LC, Wolf R, Granger D, Taylor Z (1953) Continuous recording of blood oxygen tensions by polarography. J Appl Physiol 6:189-193

4. Dunphy I, Vinogradov SA, Wilson DF (2002) Oxyphor R2 and G2: phosphors for measuring oxygen by oxygen-dependent quenching of phosphorescence. Anal Biochem 310:191-198

5. Golub AS, Pittman RN (2002) Recovery of radial PO(2) profiles from phosphorescence quenching measurements in microvessels. Comp Biochem Physiol A Mol Integr Physiol 132:169-176

6. Golub AS, Popel AS, Zheng L, Pittman RN (1997) Analysis of phosphorescence in heterogeneous systems using distributions of quencher concentration. Biophys J 73:452-465

7. Ince C, Sinaasappel M (1999) Microcirculatory oxygenation and shunting in sepsis and shock. Crit Care Med 27:1369-1377

8. Ince C, van der Sluijs JP, Sinaasappel M, Avontuur JA, Coremans JM, Bruining HA (1994) Intestinal ischemia during hypoxia and experimental sepsis as observed by NADH videofluorimetry and quenching of Pd-porphine phosphorescence. Adv Exp Med Biol 361:105-110

9. James DR, Ware WR (1986) Recovery of underlying distributions of lifetimes from fluorescent decay data. Chem Phys Lett 126:7-11

10. Johannes T, Mik EG, Ince C (2006) Dual-wavelength phosphorimetry for determination of cortical and subcortical microvascular oxygenation in rat kidney. J Appl Physiol 100:1301-1310

11. Johannes T, Mik EG, Ince C (2009) Nonresuscitated endotoxemia induces microcirculatory hypoxic areas in the renal cortex in the rat. Shock 31:97-103

12. Johannes T, Mik EG, Klingel K, Dieterich HJ, Unertl KE, Ince $\mathrm{C}$ (2009) Low-dose dexamethasone-supplemented fluid resuscitation reverses endotoxin-induced acute renal failure and prevents cortical microvascular hypoxia. Shock 31:521-528

13. Johannes T, Ince C, Klingel K, Unertl KE, Mik EG (2009) Iloprost preserves renal oxygenation and restores kidney function in endotoxemia-related acute renal failure in the rat. Crit Care Med 37:1423-1432

14. Legrand M, Almac E, Mik EG, Johannes T, Kandil A, Bezemer R, Payen D, Ince C (2009) L-NIL prevents renal microvascular hypoxia and increase of renal oxygen consumption after ischemiareperfusion in rats. Am J Physiol Renal Physiol 296:F1109-F1117

15. Leverve XM (2007) Mitochondrial function and substrate availability. Crit Care Med 35:S454-S460

16. Livesey AK, Brochon JC (1987) Analyzing the distribution of decay constants in pulse-fluorimetry using the maximum entropy method. Biophys J 52:693-706

17. Lubbers DW, Baumgartl H (1997) Heterogeneities and profiles of oxygen pressure in brain and kidney as examples of the $\mathrm{PO}_{2}$ distribution in the living tissue. Kidney Int 51:372-380
18. Luger-Hamer M, Barbiro-Michaely E, Sonn J, Mayevsky A (2009) Renal viability evaluated by the multiprobe assembly: a unique tool for the assessment of renal ischemic injury. Nephron Clin Pract 111:c29-c38

19. Mik EG, Johannes T, Zuurbier CJ, Heinen A, Houben-Weerts JH, Balestra GM, Stap J, Beek JF, Ince C (2008) In vivo mitochondrial oxygen tension measured by a delayed fluorescence lifetime technique. Biophys J 95:3977-3990

20. Mik EG, Ince C, Eerbeek O, Heinen A, Stap J, Hooibrink B, Schumacher CA, Balestra GM, Johannes T, Beek JF, Nieuwenhuis AF, van Horssen P, Spaan JA, Zuurbier CJ (2009) Mitochondrial oxygen tension within the heart. J Mol Cell Cardiol 46:943-951

21. Poole DC, Behnke BJ, McDonough P, McAllister RM, Wilson DF (2004) Measurement of muscle microvascular oxygen pressures: compartmentalization of phosphorescent probe. Microcirculation 11:317-326

22. Schurek HJ, Jost U, Baumgartl H, Bertram H, Heckmann U (1990) Evidence for a preglomerular oxygen diffusion shunt in rat renal cortex. Am J Physiol Renal Fluid Electrolyte Physiol 259:F910-F915

23. Siemiarczuk A, Wagner BD, Ware WR (1990) Comparison of the maximum entropy and exponential series methods for the recovery of distributions of lifetimes from fluorescence lifetime data. J Phys Chem 94:1661-1666

24. Springett R, Swartz HM (2007) Measurements of oxygen in vivo: overview and perspectives on methods to measure oxygen within cells and tissues. Antioxid Redox Signal 9:1295-1301

25. Stern VO, Volmer M (1919) On the quenching-time of fluorescence. Physik Zeitschr 20:183-188

26. Tsai AG, Johnson PC, Intaglietta M (2003) Oxygen gradients in the microcirculation. Physiol Rev 83:933-963

27. Tsai AG, Cabrales P, Johnson PC, Intaglietta M (2007) New phosphorescence quenching oxygen measurements technique yields unusual tissue and plasma $\mathrm{PO}_{2}$ distributions. J Appl Physiol 102:2081-2082

28. Van Bommel J, Siegemund M, ChP Henny, Ince C (2008) Heart, kidney, and intestine have different tolerances for anemia. Transl Res 151:110-117

29. Vanderkooi JM, Wilson DF (1986) A new method for measuring oxygen concentration in biological systems. Adv Exp Med Biol 200:189-193

30. Vanderkooi JM, Maniara G, Green TJ, Wilson DF (1987) An optical method for measurement of dioxygen concentration based upon quenching of phosphorescence. J Biol Chem 262:5476-5482

31. Vinogradov SA, Wilson DF (1994) Phosphorescence lifetime analysis with a quadratic programming algorithm for determining quencher distributions in heterogeneous systems. Biophys $\mathrm{J}$ 67:2048-2059

32. Whalen WJ, Nair P, Ganfield RA (1973) Measurements of oxygen tension in tissues with a micro oxygen electrode. Microvasc Res 5:254-262

33. Wilson DF, Lee WM, Makonnen S, Finikova O, Apreleva S, Vinogradov SA (2006) Oxygen pressures in the interstitial space and their relationship to those in the blood plasma in resting skeletal muscle. J Appl Physiol 101:1648-1656

34. Zheng L, Golub AS, Pittman RN (1996) Determination of $\mathrm{PO}_{2}$ and its heterogeneity in single capillaries. Am J Physiol 271:H365-H372

35. Ziemer LS, Lee WM, Vinogradov SA, Sehgal C, Wilson DF (2005) Oxygen distribution in murine tumors: characterization using oxygendependent quenching of phosphorescence. J Appl Physiol 98:1503-1510

36. Zuurbier CJ, van Iterson M (1999) Ince C (1999) Functional heterogeneity of oxygen supply-consumption ratio in the heart. Cardiovasc Res 44:488-497 